\title{
Nanoscale image of the drug/metal mono-layer interaction: Tapping AFM-IR investigations
}

\author{
Natalia Piergies ${ }^{1}(\bowtie)$, Alexandre Dazzi ${ }^{2}$, Ariane Deniset-Besseau², Jérémie Mathurin ${ }^{2}$, Magdalena Oćwieja $^{3}$, \\ Czesława Paluszkiewicz ${ }^{1}$, and Wojciech M. Kwiatek ${ }^{1}$
}

${ }^{1}$ Institute of Nuclear, Physics Polish Academy of Sciences, PL-31342 Krakow, Poland

${ }^{2}$ Laboratoire de Chimie Physique (LCP), CNRS UMR 8000, Univ. of Paris-Sud, Université Paris-Saclay, 91405 Orsay, France

${ }^{3}$ Jerzy Haber Institute of Catalysis and Surface Chemistry Polish Academy of Sciences, Niezapominajek 8, PL-30239 Krakow, Poland

(C) The Author(s) 2020.

Received: 5 January 2020 / Revised: 25 February 2020 / Accepted: 2 March 2020

\begin{abstract}
The application of metal nanoparticles as an efficient drug delivery system is one of the directions of cancer therapy development. However, this strategy requires precise information about how the drug interacts with the applied nanocarrier. In this study, atomic force microscopy combined with infrared spectroscopy (AFM-IR) was used for the first time to investigate the erlotinib adsorption structure on two different types of $15 \mathrm{~nm}$ metal nanoparticle mono-layers, namely, silver nanoparticle (AgNP) and gold nanoparticle (AuNP) mono-layers. Because the metal nanoparticles are loosely bound samples, only the tapping AFM-IR mode is suitable for the collection of IR maps and spectra for such a system. The obtained results indicated the relevance of the AFM-IR technique for characterizing drug interactions with a metal mono-layer surface. The investigated drug interacts with the AgNPs mainly through phenyl rings and methoxy moieties, while quinazoline, amino, and ethoxy moieties appear to be farther from the surface. For the AuNPs, the interaction occurs through both the phenyl ring and the quinazoline moiety. Additionally, the aliphatic groups of erlotinib directly participate in this interaction. The novelty of the present work is also related to the use of the tapping AFM-IR mode to study metal NP mono-layers with a drug adsorbed on them. The collected IR maps for the most enhanced erlotinib bands show specific areas with very high signal intensity. The connection between these areas and the "hot spots" typical for the surface plasmon resonance phenomenon of metals is considered.
\end{abstract}

\section{KEYWORDS}

metal nanoparticle mono-layer, drug's adsorption, infrared nanospectroscopy, atomic force microscopy, erlotinib

\section{Introduction}

Currently, the development of target-cell-specific delivery as a new approach to increase the cytotoxic effects of drugs inside cancer cells is highly desirable [1]. The application of drug vehicles with appropriate sizes and shapes provides possibilities to enhance the concentration of anticancer agents at the target site and at the same time ensures protection against bothersome side effects $[2,3]$, such as those induced by the internalization of the drug inside non-pathological cells that block the activity of physiological processes $[4,5]$. However, the immobilization of anticancer drugs on the carrier surface may result in their deactivation. Therefore, to optimize the design of effective drug-nanocarrier conjugates, it is crucial to perform a detailed characterization of the geometric structure of an anticancer agent after its loading on the appropriate surface.

Metal nanoparticles as drug vehicles ensure control of the adsorption of molecules on their surface. It has been proven that surface-enhanced vibrational spectroscopy methods, such as surface-enhanced Raman spectroscopy (SERS) [6] and surface-enhanced infrared absorption (SEIRA) [7] spectroscopy, provide possibilities to investigate how molecules adsorb on metal surfaces. Pearce and Sheppard described the metal-surface selection rules for infrared spectroscopy (IR) spectra of ethylene adsorbed on various metal surfaces. Since the detected spectral signal strongly depends on the particular bond orientation of the entity immobilized on the metal, this signal provides a detailed characterization of molecular adsorption; this is because only vibrations that induce dipole changes perpendicular to the metal surface contribute to the IR spectrum. Moreover, the bands related to modes with dipole moments parallel to the surface should be suppressed [8]. Pearce and Sheppard implied that the abovementioned restrictions apply only for highly polarizable materials [9]. Additionally, Greenler and co-workers [10] postulated that the metal selection rules are applicable for nanoparticles larger than $2 \mathrm{~nm}$, while for smaller nanoparticles, the applicability of these rules is limited. As a consequence of these surface selection rules, IR spectroscopy ensures that specific information can be obtained about biologically active molecules immobilized onto a large metal nanocarrier surface. Moreover, Osawa reported that adsorption of a molecule on a metal surface produces an extremely strong enhancement of infrared absorption, which leads to SEIRA [7, 11]. This phenomenon is related to the excitation of localized plasmons of the metal nanostructures by infrared light and corresponds with the well-described SERS effect [7, 8, 11-13]. The electromagnetic mechanism of SEIRA explains such enhancement of the IR signal to be a result of dipole induction 
in the nanostructures, generating local electromagnetic fields much stronger than those of the incident photons [11, 14, 15]. Typically, the localized surface plasmon resonance (LSPR) of noble metals is associated with a strong absorption band in the visible region $(\sim 360-720 \mathrm{~nm})$ [16]. However, due to the dipole coupling between nanostructures, the metal resonance band can shift to the mid-infrared region, and the enhancement of infrared absorption is still observed [17-19]. Such a coupling phenomenon has been proven, especially for $\mathrm{Ag}$ and $\mathrm{Au}$ nanoparticle arrays with relatively small lattice spacings of less than $100 \mathrm{~nm}[18,19]$. Based on these considerations, the precise adsorption geometry characterization of a drug loaded on metal carriers using IR radiation is possible.

The usual IR methods are diffraction limited, which leads to a relatively low spatial resolution $(\sim 5-10 \mu \mathrm{m})[20,21]$. Therefore, the obtained spectral data for particles with nanometre dimensions seem to be too general to illustrate subtle local changes in the adsorption orientation of the molecule on the investigated nanosurface. The combination of atomic force microscopy with infrared spectroscopy (AFM-IR) overcomes this conventional limit of spatial resolution. AFM-IR combines the nanometre resolution of atomic force microscopy with the ability to perform chemical analysis owing to the acquisition of local infrared spectra [22-25]. In this approach, the local absorption is ruled by the photothermal effect. Pulsed IR radiation from a tuneable laser source initiates a thermal expansion probed by the AFM tip in contact with the surface [26]. As the expansion is directly proportional to the absorption coefficient, local IR spectra are generated [23]. The spatial resolution achieved by this hybrid technique is imposed by the radius of the AFM tip ( $10 \mathrm{~nm})$ [22]. AFM-IR is widely used for various applications, i.e., cancer cell $[27,28]$ and bacteria $[29,30]$ investigations, characterization of lipid distribution in human skin [31], protein secondary structure in cataractous human lenses [32], and polymers [33] and cultural heritage analysis [34]. Additionally, the development of the tapping AFM-IR mode has opened new possibilities in the analysis of soft and loosely bound samples such as drug-loaded polymeric nanoparticles [35], drugs partitioned within lipid-polymer hybrid films [36] and drugs adsorbed on aggregated metal nanoparticles [37, 38].

In this study, AFM-IR was applied to interpret the adsorption behaviour of a tyrosine kinase inhibitor, namely, erlotinib, immobilized on silver $(\mathrm{Ag})$ and gold $(\mathrm{Au})$ nanoparticle monolayers. This drug is approved in targeted therapy for patients with non-small cell lung cancer (NSCLC) [39] after progression on prior chemotherapy $[40,41]$. The association of erlotinib with nanoparticle carriers should improve its delivery and decrease its unfavourable cytotoxic effects (e.g., skin rash, diarrhoea, scalp hair loss, increased facial hair) [42, 43]. Previously published SERS data have shown that erlotinib adsorbed on silver nanoparticles dispersed in suspensions manifests a strong interaction with the metal surface [44]. However, those SERS data do not answer the question of how the drugs interact locally with the applied metal nanoparticles. Additionally, it is still an open question of whether the surface selection rules commonly known for the conventional SEIRA technique could be applied to interpret the AFM-IR results of molecules immobilized on a metal surface. If surface-enhanced phenomena are also observed in AFM-IR spectroscopy, the results obtained with this technique should be able to answer all of these questions. In the first part of the presented studies, the way that erlotinib adsorbs on AgNP and AuNP mono-layers has been discussed. In the second part, the AFM-IR intensity maps visualizing areas with very high intensity and the relation of these areas with the "hot spots" characteristic for surface plasmon resonance have been considered. To the best of the authors' knowledge, these are the first investigations using the tapping AFM-IR mode to study drug adsorption on metal nanoparticle mono-layers.

\section{Experimental}

\subsection{Synthesis of AgNPs and AuNPs}

Aqueous suspensions of silver and gold nanoparticles were obtained by a chemical reduction method according to the procedures described in previous literature reports $[45,46]$. Then, the suspensions were purified from the unreacted compounds and characterized by the use of various physicochemical methods. It was found that the concentrations of the stock solutions were 80 and $120 \mathrm{mg} / \mathrm{L}$ for the suspensions of AgNPs and AuNPs, respectively. The $\mathrm{pH}$ of these suspensions was 5.6 , and the conductivity did not exceed $20 \mu \mathrm{S} / \mathrm{cm}$. The measurements conducted using dynamic light scattering (DLS) revealed that the hydrodynamic diameters of the synthesized nanoparticles were $15 \pm 3 \mathrm{~nm}$ and remained unchanged up to an ionic strength of $0.03 \mathrm{M}[45,46]$. The average size of the nanoparticles determined by DLS was in agreement with data obtained from transmission electron microscopy (TEM) imaging. From electrophoretic mobility measurements, it was found that these citrate-stabilized nanoparticles were negatively charged. The zeta potential of the nanoparticles significantly increased with ionic strength, and at $0.01 \mathrm{M}$, the value was $-55 \pm 3 \mathrm{mV}$ and $-51 \pm 2 \mathrm{mV}$ for AgNPs and AuNPs, respectively.

\subsection{Metal mono-layer preparation}

Homogeneous mono-layers of AgNPs and AuNPs deposited on $\mathrm{CaF}_{2}$ windows were prepared by applying electrostatically driven self-organization of the nanoparticles at the solid/liquid interface $[45,46]$. Because citrate-stabilized nanoparticles and the $\mathrm{CaF}_{2}$ window exhibit negative surface charges, the procedure previously applied to reverse the charge of mica $[45,46]$ was adapted for the $\mathrm{CaF}_{2}$ window. The cationic polyelectrolyte poly(allylamine hydrochloride) ( $\mathrm{PAH}$ ) with a molar mass of $70 \mathrm{kDa}$ was used for modification of the $\mathrm{CaF}_{2}$ surface. It should be noted that PAH does not give a strong IR spectral signal; thus, it has been used for such experiments [47]. For the appropriate modification, freshly clean $\mathrm{CaF}_{2}$ windows were placed in the vertical position into $20 \mathrm{mg} / \mathrm{L}$ PAH solutions with an ionic strength of $0.01 \mathrm{M}$ and $\mathrm{pH}$ 5.6. This diffusioncontrolled deposition process was conducted under ambient conditions at a temperature of $25^{\circ} \mathrm{C}$. The windows were stored for $20 \mathrm{~min}$ and then rinsed with ultrapure water to remove unbound PAH molecules. Afterwards, the PAH-modified $\mathrm{CaF}_{2}$ windows were placed into AgNP and AuNP stock suspensions with an ionic strength of $0.01 \mathrm{M}$ regulated by the addition of sodium chloride [45]. Taking into account that the nanoparticle deposition was carried out under diffusion-controlled conditions and based on the results of studies previously obtained for mono-layers formed on PAH-modified mica sheets $[45,46]$, it was estimated that the deposition time needed for the formation of dense metal nanoparticle mono-layers should not be less than $4 \mathrm{~h}$. After this period of time, to remove unbound nanoparticles and the excess sodium chloride, the mono-layers were washed with ultrapure water. Finally, the modified windows were dried in air at $25{ }^{\circ} \mathrm{C}$ and used immediately after preparation.

The surface concentration of the nanoparticles (number of 
particles per unit area of the substrate) on the PAH-modified $\mathrm{CaF}_{2}$ windows was quantitatively determined using SEM micrographs obtained from a JEOL JSM-7500F field emission microscope [45]. After determining the surface concentrations of the nanoparticles and their average size, the dimensionless coverage of the mono-layers was calculated according to the procedure described previously $[45,46]$. It was found that the mono-layer coverage was 0.33 and 0.31 in the case of AgNPs and AuNPs, respectively. It is worth mentioning that these values are in accordance with those reported for the metal nanoparticle mono-layers formed on $\mathrm{PAH}$-modified mica $[45,46]$.

\subsection{Sample preparation}

The investigated drug, namely, (N-(3-ethynylphenyl)-6,7-bis(2methoxyethoxy)quinazolin-4-amine hydrochloride) (erlotinib hydrochloride; purity 99.75\%), was purchased from Selleckchem company and used without any purification. The powder was dissolved in deionized water. A drop of the drug solution at a concentration of $10^{-4} \mathrm{M}$ was placed on the $\mathrm{CaF}_{2}$ window and on the prepared metal mono-layer in order to measure spectra for non-oriented and oriented molecules, respectively, and left to dry.

\subsection{AFM-IR spectroscopy measurements}

The experiments were performed using a NanoIR2 Anasys Instrument system combined with a multichip tuneable quantum cascade laser (QCL; MIRcat-QT Daylight Solutions) used as an infrared source. The spectral range selected was $1,335-1,675 \mathrm{~cm}^{-1}$. The spectra were collected with $1 \mathrm{~cm}^{-1}$ spectral resolution, and to increase the signal-to-noise ratio (SNR) at each analysed point, 3 spectra were averaged. Because the metal nanoparticles represent a sample that is not bound strongly enough to the surface, tapping AFM-IR mode was applied for spectral collection and mapping. For this purpose, commercially available silicon gold-coated tips $(70 \mathrm{~nm}$ thick gold coating, $225 \mu \mathrm{m}$ nominal length, and $28 \mu \mathrm{m}$ nominal width) with a resonance frequency of $75 \mathrm{kHz}$ and force constant of $3 \mathrm{~N} / \mathrm{m}$ were used. The AFM-IR maps were collected at a scan rate of $0.5 \mathrm{~Hz}$ with $x$ and $y$ sampling of 500 pts. The tapping mode setpoint and drive strength were set to $4.43 \mathrm{~V}$ and $70 \%$, respectively. During the measurements, $26 \%$ of the average QCL laser power $(0.5 \mathrm{~W})$ with a pulse length of $460 \mathrm{~ns}$ was applied. After obtaining each series of spectra, the AFM topography was collected in order to monitor the sample condition. Additionally, the IR maps and topographic images were collected at the same time. During the measurements, no thermal damage occurred within the sample. The experimental scheme is presented in Fig. 1.

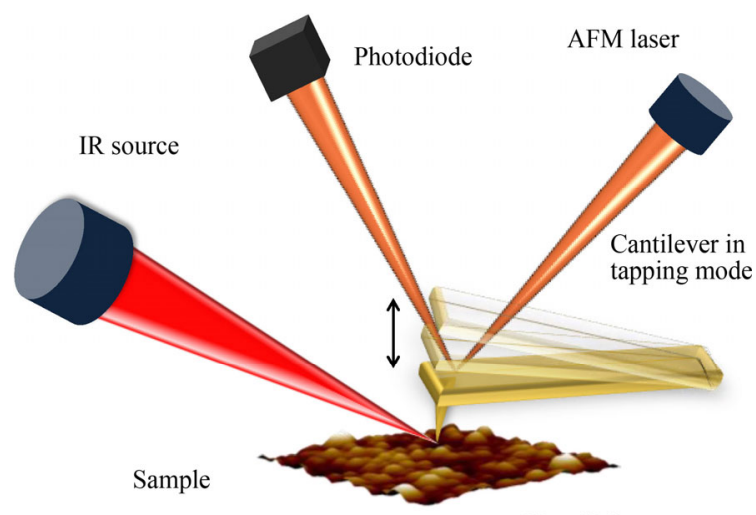

NanoIR2 system

Figure 1 Experimental scheme.

\subsection{Data processing}

The AFM-IR spectra and 2D intensity maps were generated using dedicated Analysis Studio software version 3.14 for the NanoIR2 system. The 3D intensity maps were visualized using Mountainsmap 7.3 software (Digital Surf, France). The spectra were processed with Omnic 32 software. All presented spectra were smoothed using the Savitzky-Golay function (3rd-order polynomial and 5 data points). Moreover, multipoint baseline correction (5 points) was applied before normalization. It should be noted that this processing did not affect the relative intensities of the bands. Before spectral interpretation, min-max normalization was used.

\section{Results and discussion}

Prior to the tapping AFM-IR measurements, the AgNP and AuNP supports were characterized using AFM. Figure 2 shows the topography of the metal mono-layers before and after drug adsorption. The nanoparticles exhibit a spherical shape, and in both cases, the diameter is $\sim 15 \mathrm{~nm}$. The mono-layers were assembled on the $\mathrm{CaF}_{2}$ windows using a procedure that provides the highest possible degree of coverage.

As confirmed [7, 47], the surface enhancement observed in IR spectroscopy is associated with the morphology of the metal structure and strongly increases with the size and thickness of the metal island. Thus, mono-layers with a high degree of nanoparticle coverage are expected to ensure large absorption enhancements. AFM-IR characterization of the molecular structure of the randomly oriented (non-adsorbed) drug was also performed. Figure 3(a) presents the AFM-IR spectrum of erlotinib alone, and in Table 1, all wavenumbers and assignments of the bands are listed. The band assignment analysis was performed based on previously published studies of the erlotinib structure coupled with density functional theory (DFT) calculations [48]. Additionally, the corresponding data for the main chemical groups present in the molecules such as aniline [49], pyrimidine [50,51], and phenylacetylene [52] were taken into consideration.

The most intense spectral features observed in the erlotinib spectrum are due to the phenyl ring and quinazoline moiety vibrations. Namely, the bands at 1,632, 1,607, 1,570, and $1,445 \mathrm{~cm}^{-1}$ are assigned to $v(\mathrm{CC})_{\text {Phe, }} v(\mathrm{CC})_{\text {Phe, }} v(\mathrm{CC})_{\text {Phe }} / \rho_{\mathrm{b}}(\mathrm{CH})_{\text {Phe, }}$ and $v(\mathrm{CH})_{\text {Phe }}$ vibrations, respectively. Additionally, the
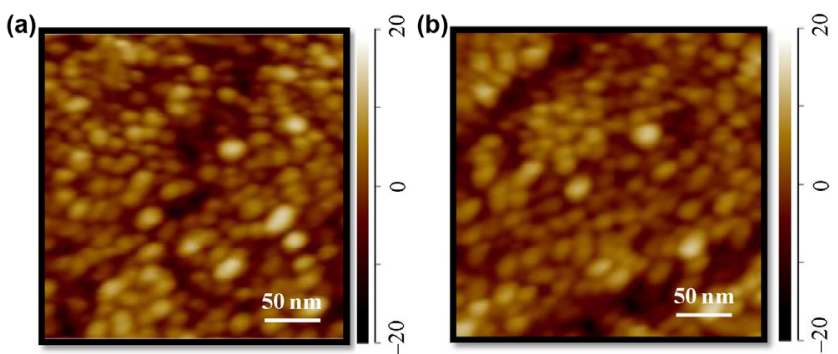

(c)
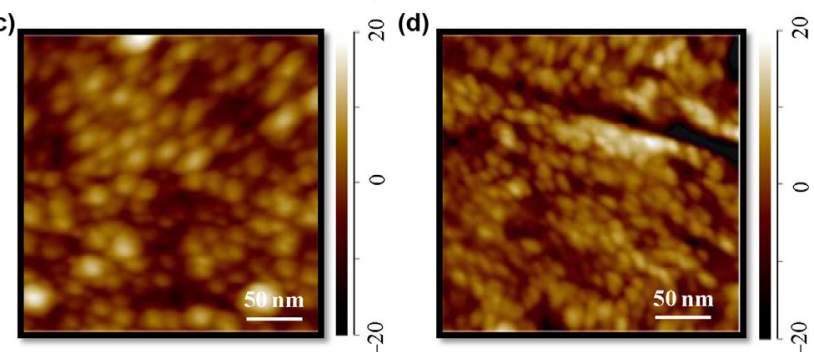

Figure 2 AFM topography of the Ag NPs ((a) and (c)) and AuNPs ((b) and (d)) mono-layers before and after the drug adsorption, respectively. 


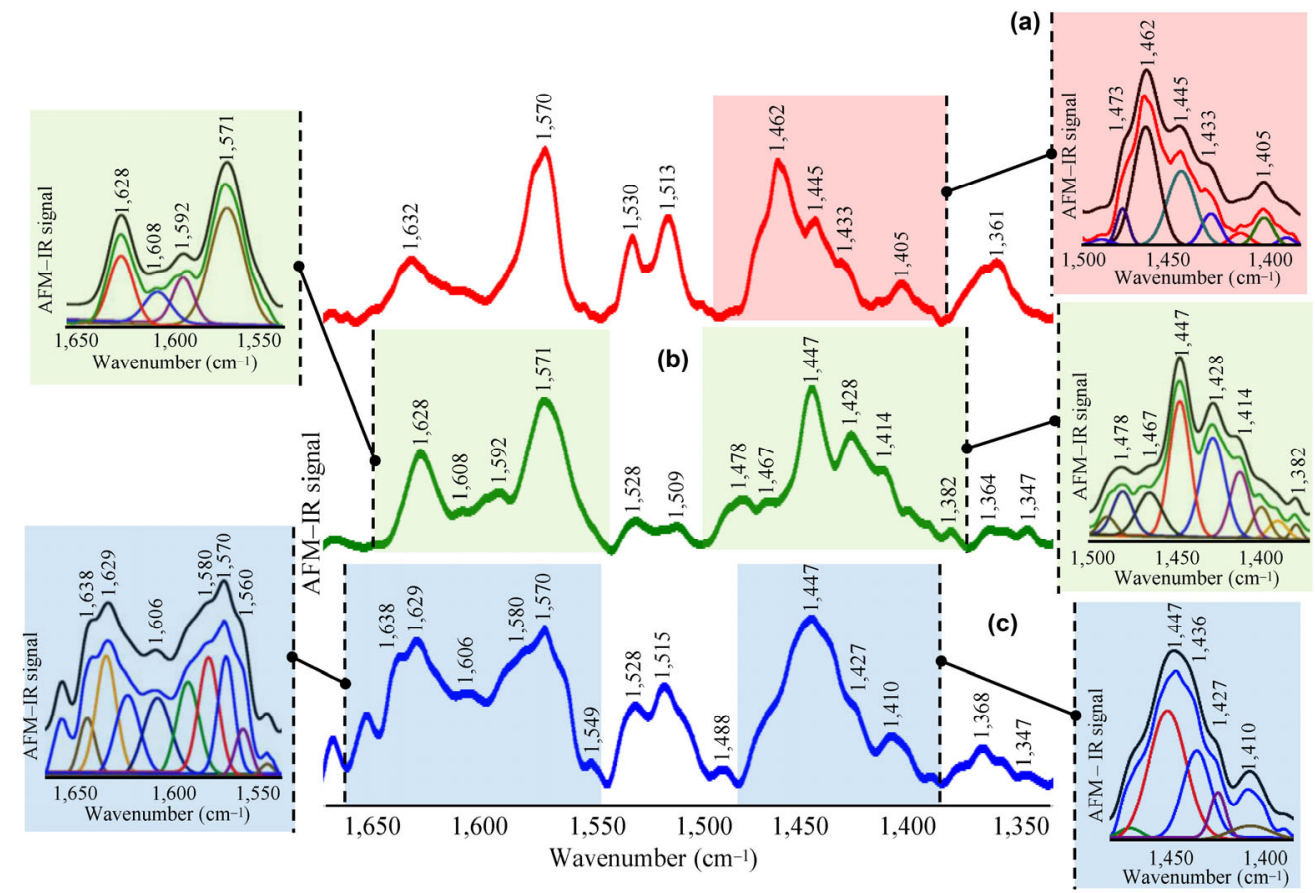

Figure 3 AFM-IR spectra of erlotinib (a) and erlotinib immobilized on the colloidal AgNPs (b) and AuNPs (c) mono-layers in the spectral range of $1,675-1,335 \mathrm{~cm}^{-1}$ together with the performed curve fitting; the black solid lines illustrate the composite result spectra, while red, green, and blue solid lines represent the appropriate original spectra.

Table 1 The suggested assignments together with the wavenumbers $(v)$ and full width at half maximum (FWHM) for the significant AFM-IR bands of erlotinib alone and adsorbed on the AgNPs and AuNPs mono-layers [44, 48-52]

\begin{tabular}{|c|c|c|c|c|c|c|}
\hline \multirow[b]{2}{*}{ Band assignments ${ }^{\mathrm{a}}$} & \multicolumn{2}{|c|}{ Erlotinib } & \multicolumn{2}{|c|}{ Erlotinib-AgNPs } & \multicolumn{2}{|c|}{ Erlotinib-AuNPs } \\
\hline & AFM-IR & $\begin{array}{c}\text { FWHM } \\
\left(\mathrm{cm}^{-1}\right)\end{array}$ & AFM-IR & $\begin{array}{c}\text { FWHM } \\
\left(\mathrm{cm}^{-1}\right)\end{array}$ & AFM-IR & $\begin{array}{c}\text { FWHM } \\
\left(\mathrm{cm}^{-1}\right)\end{array}$ \\
\hline$v(\mathrm{CC})_{\text {Phe, }}, \rho_{\mathrm{b}}(\mathrm{NH}), v(\mathrm{CN})_{\mathrm{Q}}$ & 1,632 & 15 & 1,628 & 17 & 1,629 & 16 \\
\hline$v(\mathrm{CC})_{\mathrm{Q}}$ & 1,618 & 13 & - & - & 1,615 & 13 \\
\hline$v(\mathrm{CC})_{\mathrm{Phe}}, \rho_{\mathrm{b}}(\mathrm{NH}), v(\mathrm{C}=\mathrm{N})_{\mathrm{Q}}, v(\mathrm{CC})_{\mathrm{Q}}$ & 1,607 & 10 & 1,608 & 17 & 1,606 & 24 \\
\hline$v(\mathrm{CC})_{\mathrm{Q}}$ & - & - & 1,592 & 12 & 1,592 & 16 \\
\hline$\rho_{\mathrm{b}}(\mathrm{NH}), v(\mathrm{NC})_{\mathrm{Q}-\mathrm{NH}}, v(\mathrm{C}=\mathrm{N})_{\mathrm{Q}}, v(\mathrm{CC})_{\mathrm{C} \Phi \mathrm{C}}, \rho_{\mathrm{b}}(\mathrm{CH})_{\mathrm{Phe}}, v(\mathrm{CC})_{\mathrm{Q}}$ & 1,578 & 14 & - & - & 1,580 & 19 \\
\hline$v(\mathrm{CC})_{\text {Phe }}$ & 1,570 & 12 & 1,571 & 22 & 1,570 & 16 \\
\hline$v(\mathrm{C}=\mathrm{N})_{\mathrm{Q}}, v(\mathrm{CN})_{\mathrm{Q}}, v(\mathrm{CC})_{\mathrm{Q}}$ & - & - & - & - & 1,560 & 6 \\
\hline$\delta(\mathrm{Q})$ & - & - & - & - & 1,549 & 10 \\
\hline$v(\mathrm{Phe}), \rho_{\mathrm{b}}(\mathrm{NH})$ & 1,530 & 10 & 1,528 & 13 & 1,528 & 16 \\
\hline$\rho_{\mathrm{w}}\left(\mathrm{OCH}_{3}\right)$ & 1,513 & 13 & - & - & 1,516 & 10 \\
\hline$\rho_{\mathrm{s}}\left(\mathrm{CH}_{2}\right)_{\mathrm{OCH}_{2}}, \rho_{\mathrm{s}}\left(\mathrm{CH}_{2}\right)_{\mathrm{CH}_{2} \mathrm{O}}, \rho_{\mathrm{s}}\left(\mathrm{CH}_{2}\right)_{\mathrm{CH}_{3}}$ & - & - & 1,509 & 15 & 1,506 & 16 \\
\hline$\rho_{\mathrm{b}}(\mathrm{CH})_{\text {Phe }}, \delta(\mathrm{Phe})$ & - & - & - & - & 1,488 & 10 \\
\hline$\rho_{\mathrm{w}}\left(\mathrm{CH}_{2}\right)_{\mathrm{CH}_{3}}$ & 1,473 & 6 & 1,479 & 11 & 1,470 & 15 \\
\hline$\rho_{\mathrm{b}}(\mathrm{CH})_{\mathrm{Q}}, v(\mathrm{CN})_{\mathrm{Q}}, v(\mathrm{CC})_{\mathrm{Q}}$ & 1,462 & 14 & 1,467 & 19 & - & - \\
\hline$v(\mathrm{CH})_{\text {Phe }}$ & 1,445 & 15 & 1,447 & 13 & 1,447 & 17 \\
\hline$\rho_{\mathrm{w}}\left(\mathrm{CH}_{2}\right)_{\mathrm{CH}_{3}}, \rho_{\mathrm{w}}\left(\mathrm{CH}_{2}\right)_{\mathrm{OCH}_{2}}, \rho_{\mathrm{w}}\left(\mathrm{CH}_{2}\right)_{\mathrm{CH}_{2} \mathrm{O}}$ & 1,433 & 10 & 1,428 & 15 & 1,436 & 17 \\
\hline$\rho_{\mathrm{w}}\left(\mathrm{CH}_{2}\right)_{\mathrm{CH}_{3}}, \rho_{\mathrm{w}}\left(\mathrm{CH}_{2}\right)_{\mathrm{OCH}_{2}}, \rho_{\mathrm{w}}\left(\mathrm{CH}_{2}\right)_{\mathrm{CH}_{2} \mathrm{O}}$ & - & - & - & - & 1,427 & 9 \\
\hline$\rho_{\mathrm{w}}\left(\mathrm{CH}_{2}\right)_{\mathrm{CH}_{3}}, \rho_{\mathrm{w}}\left(\mathrm{CH}_{2}\right)_{\mathrm{OCH}_{2}}, \rho_{\mathrm{w}}\left(\mathrm{CH}_{2}\right)_{\mathrm{CH}_{2} \mathrm{O}}, \rho_{\mathrm{b}}(\mathrm{NH}), \delta(\mathrm{Phe}), \delta(\mathrm{Q})$ & 1,416 & 10 & 1,414 & 13 & 1,410 & 16 \\
\hline$v(\mathrm{C}=\mathrm{N})_{\mathrm{Q}}, v(\mathrm{CC})_{\mathrm{Q}}, \rho_{\mathrm{b}}(\mathrm{CH})_{\mathrm{Q}}, \rho_{\mathrm{b}}(\mathrm{NH})$ & 1,405 & 10 & 1,402 & 20 & - & - \\
\hline$\rho_{\mathrm{w}}\left(\mathrm{CH}_{2}\right)_{\mathrm{CH}_{3}}, \rho_{\mathrm{w}}\left(\mathrm{CH}_{2}\right)_{\mathrm{OCH}_{2}}, \rho_{\mathrm{w}}\left(\mathrm{CH}_{2}\right)_{\mathrm{CH}_{2} \mathrm{O}}$ & - & - & 1,382 & 8 & 1,381 & 9 \\
\hline$\rho_{\mathrm{b}}(\mathrm{CH})_{\mathrm{Q}}, v(\mathrm{CC})_{\mathrm{Q}}, \rho_{\mathrm{b}}(\mathrm{CH})_{\mathrm{Phe}}$ & 1,373 & 16 & - & - & 1,377 & 10 \\
\hline$\rho_{\mathrm{w}}\left(\mathrm{CH}_{2}\right)_{\mathrm{CH}_{2} \mathrm{O}}, \rho_{\mathrm{w}}\left(\mathrm{CH}_{2}\right)_{\mathrm{OCH}_{2}}, \rho_{\mathrm{b}}(\mathrm{NH}), \rho_{\mathrm{b}}(\mathrm{CH})_{\mathrm{Phe}}, v(\mathrm{NC})_{\mathrm{Q}-\mathrm{NH}}, v(\mathrm{NC})_{\mathrm{Q}}$ & 1,361 & 16 & 1,364 & 17 & 1,368 & 10 \\
\hline$\rho_{\mathrm{b}}(\mathrm{CH})_{\mathrm{Q}}, \delta(\mathrm{Q})$ & - & - & 1,347 & 15 & 1,347 & 16 \\
\hline
\end{tabular}

${ }^{\mathrm{a} A b b r e v i a t i o n s:} v$, stretching; $\rho_{\mathrm{b}}$, bending; $\rho_{\mathrm{w}}$, wagging; $\rho_{\mathrm{s}}$, scissoring; $\delta$, deformation; Phe, phenyl ring; Q, quinazoline group.

deformation vibration of the phenyl ring $[\delta(\mathrm{Phe})]$ contributes to the weak intensity band at $1,416 \mathrm{~cm}^{-1}$ (see Table 1 ). For the quinazoline moiety, the bands appearing at $1,618,1,578,1,462$, and 1,405 are attributed to the $v(\mathrm{CC})_{\mathrm{Q}}, v(\mathrm{C}=\mathrm{N})_{\mathrm{Q}} / v(\mathrm{CC})_{\mathrm{Q}}$, $\rho_{\mathrm{b}}(\mathrm{CH})_{\mathrm{Q}} / v(\mathrm{CN})_{\mathrm{Q}} / v(\mathrm{CC})_{\mathrm{Q}}$, and $v(\mathrm{C}=\mathrm{N})_{\mathrm{Q}}$ modes, respectively. The vibrational motions of the aliphatic groups of erlotinib 
are also visible in the AFM-IR spectrum. For the methoxy and ethoxy moieties, the characteristic medium and weak intensity bands, specifically, $\rho_{\mathrm{s}}\left(\mathrm{CH}_{2}\right)_{\mathrm{OCH}_{2}} / \rho_{\mathrm{s}}\left(\mathrm{CH}_{2}\right)_{\mathrm{CH}_{3}} / \rho_{\mathrm{s}}\left(\mathrm{CH}_{2}\right)_{\mathrm{CH}_{2} \mathrm{O}}$, and $\rho_{\mathrm{w}}\left(\mathrm{CH}_{2}\right)_{\mathrm{CH}_{3}}$, and $\rho_{\mathrm{w}}\left(\mathrm{CH}_{2}\right)_{\mathrm{CH}_{3}} / \rho_{\mathrm{w}}\left(\mathrm{CH}_{2}\right)_{\mathrm{OCH}_{2}} / \rho_{\mathrm{w}}\left(\mathrm{CH}_{2}\right)_{\mathrm{CH}_{2} \mathrm{O}}$, and $\rho_{\mathrm{w}}\left(\mathrm{CH}_{2}\right)_{\mathrm{CH}_{2} \mathrm{O}} / \rho_{\mathrm{w}}\left(\mathrm{CH}_{2}\right)_{\mathrm{OCH}_{2}}$ appear at 1,513 , and 1,473 and 1,433 , 1,416 , and $1,361 \mathrm{~cm}^{-1}$, respectively. In the case of the amino group, the medium band associated with the $\rho_{\mathrm{b}}(\mathrm{NH})$ mode appears at $1,530 \mathrm{~cm}^{-1}$. This vibration also contributes to the bands at 1,578,1,416, and 1,361 $\mathrm{cm}^{-1}$. The observed AFM-IR spectral pattern for non-adsorbed erlotinib corresponds to the previously published results obtained by conventional Fourier transform IR spectroscopy in ATR mode [48]. However, some changes, especially in the relative intensities of the particular bands, are noted, especially for the bands at $\sim 1,632$ and $\sim 1,445 \mathrm{~cm}^{-1}$. It is commonly known that how a sample is prepared for measurements may influence the acquired spectral information. Parameters such as the physical state of the sample [53], solvent (solvent effect) [54], solution $\mathrm{pH}$ [48], and polarization effect of crystal samples [55] determine the relative intensity of the particular bands in the vibrational spectrum. Thus, the same sample preparation was applied in the AFM-IR experiments for the non-adsorbed and adsorbed drug (please see the Sample preparation section). Figure 3(b) illustrates the AFM-IR spectrum collected for erlotinib immobilized onto $15 \mathrm{~nm} \mathrm{Ag} \mathrm{nanoparticles} \mathrm{(AgNPs).} \mathrm{For} \mathrm{each}$ sample region, eight spectra were recorded at different locations. The spectra were reproducible; however, small differences $(\sim 5 \%)$ in some band intensities were noticed. Such a spectral pattern is commonly observed in surface-enhanced vibrational spectroscopy techniques [56]. The most repeatable spectrum was taken for further analysis. The adsorption of erlotinib on the AgNP mono-layer induces significant spectral changes in the relative intensities and widths of the bands in comparison with the AFM-IR spectrum of non-adsorbed molecules. This phenomenon indicates that the surface selection rules typical for conventional SEIRA spectra also affect the AFM-IR signal of the adsorbed erlotinib. Therefore, the AFM-IR technique can be applied to characterize the molecular orientation of the adsorbed molecules. As discussed in the Introduction, molecular oscillations with dipoles perpendicular to the metal surface should dominate the IR spectrum [9]. In the AFM-IR spectrum of erlotinib immobilized on the AgNP mono-layer (erlotinib-AgNPs), the most intense bands are attributed to phenyl ring vibrational motions. These bands are visible at $1,628,1,608,1,571$, and $1,447 \mathrm{~cm}^{-1}$ and are associated with $v(\mathrm{CC})_{\text {Phe }}, v(\mathrm{CC})_{\text {Phe }} / \rho_{\mathrm{b}}(\mathrm{CH})_{\text {Phe, }}$ and $v(\mathrm{CH})_{\text {Phe }}$ vibrations, respectively. The significant enhancement of these spectral features in comparison with the corresponding bands for non-adsorbed erlotinib (NA erlotinib) indicates that the phenyl ring is oriented perpendicularly on the AgNP surface and strongly interacts with this mono-layer (Fig. 3). This indication is also confirmed by the observed bandwidth changes noted between the AFM-IR spectra of NA erlotinib and erlotinib-AgNPs. More specifically, the full width at half maximum (FWHM) of the bands at $1,628,1,608,1,571$, and $1,447 \mathrm{~cm}^{-1}$ is $17,17,22$, and $13 \mathrm{~cm}^{-1}$, respectively, whereas the FWHM of the corresponding bands for the non-adsorbed drug are $15,10,12$, and $15 \mathrm{~cm}^{-1}$ (see Table 1). Different phenomena for the quinazoline moiety are observed. Here, the bands of the AFM-IR spectrum of erlotinib-AgNPs decrease in intensity. These bands occur at $1,592 \mathrm{~cm}^{-1}\left[v(\mathrm{C}=\mathrm{N})_{\mathrm{Q}} / v(\mathrm{CC})_{\mathrm{Q}}\right], 1,467 \mathrm{~cm}^{-1}\left[\rho_{\mathrm{b}}(\mathrm{CH})_{\mathrm{Q}} / v(\mathrm{CN})_{\mathrm{Q}} /\right.$ $\left.v(\mathrm{CC})_{\mathrm{Q}}\right]$, and $1,402 \mathrm{~cm}^{-1}\left[v(\mathrm{C}=\mathrm{N})_{\mathrm{Q}}\right]$. The presence of these spectral features in the spectrum suggests that the quinazoline moiety is located at a certain distance from the surface and only participates (i.e., does not interact directly) in erlotinib adsorption on the AgNP mono-layer. However, the aliphatic functional groups of erlotinib appear to be strongly involved in the considered interaction. The strong and medium intensity bands visible at $1,479,1,428$ and $1,414 \mathrm{~cm}^{-1}$ are attributed to $\rho_{\mathrm{w}}\left(\mathrm{CH}_{2}\right)_{\mathrm{CH}_{3}}$. The shift in the position of these bands $(\Delta v=$ $\left.\sim 6 \mathrm{~cm}^{-1}\right)$ and changes in their width $\left(\Delta_{\mathrm{FWHM}}=\sim 5 \mathrm{~cm}^{-1}\right)$ in comparison with those in the corresponding AFM-IR spectrum for the randomly oriented drug are significant (see Table 1). At the same time, the bands associated with the amino and ethoxy moieties exhibit decreased intensities. This effect is especially observed for the bands at 1,528 and at 1,509, 1,364 $\mathrm{cm}^{-1}$, attributed to the $\rho_{\mathrm{b}}(\mathrm{NH})$ and $\rho_{\mathrm{s}}\left(\mathrm{CH}_{2}\right)_{\mathrm{OCH}_{2}} / \rho_{\mathrm{s}}\left(\mathrm{CH}_{2}\right)_{\mathrm{CH} 2 \mathrm{O}}$ vibrations, respectively. The abovementioned spectral patterns indicate that the methoxy moiety is situated perpendicular to the metal surface and contributes significantly to drug adsorption on the AgNPs, while the amino and ethoxy groups are located at a certain distance from the metal mono-layer. The erlotinib orientation on the AgNPs distinguished at nanoscale spatial resolution by the AFM-IR technique corresponds very well with the previously published results obtained using SERS for this drug immobilized on aggregated AgNPs [44].

Different adsorption behaviours of erlotinib immobilized on the AuNP mono-layer (erlotinib-AuNPs) are observed. The appearance of variations in the relative intensities of bands due to quinazoline motions suggests that this moiety plays a significant role in the adsorption of the drug on the AuNPs. These interactions are manifested by the significant enhancement and broadening of AFM-IR bands for erlotinib immobilized on this metal mono-layer in comparison with those of the corresponding spectral pattern detected for the randomly oriented drug. In brief, the bands at $1,615 \mathrm{~cm}^{-1}\left[v(\mathrm{CC})_{\mathrm{Q}}\right]$, $1,592 \mathrm{~cm}^{-1}\left[v(\mathrm{CC})_{\mathrm{Q}}\right], 1,580 \mathrm{~cm}^{-1}\left[v(\mathrm{C}=\mathrm{N})_{\mathrm{Q}} / v(\mathrm{CC})_{\mathrm{Q}}\right], 1,560 \mathrm{~cm}^{-1}$ $\left[v(\mathrm{C}=\mathrm{N})_{\mathrm{Q}} / v(\mathrm{CN})_{\mathrm{Q}} / v(\mathrm{CC})_{\mathrm{Q}}\right]$, and $1,549 \mathrm{~cm}^{-1}[\delta(\mathrm{Q})]$ show a broadening effect of $\sim 5 \mathrm{~cm}^{-1}$ and a shift in their position of $\sim 3 \mathrm{~cm}^{-1}$ (see Table 1). Such a shift in the band position is proved as evidence of the interaction between this particular moiety and the metal surface [57]. In the case of the phenyl ring, its interaction with the AuNP mono-layer appears to be even stronger than that with the AgNP mono-layer. The bands appearing at 1,629 and $1,570,1,488,1,447 \mathrm{~cm}^{-1}$ and assigned to the $v(\mathrm{CC})_{\text {Phe, }} \rho_{\mathrm{b}}(\mathrm{CH})_{\text {Phe }} / \delta(\mathrm{Phe})$, and $v(\mathrm{CH})_{\text {Phe }}$ modes, respectively, indicate stronger intensities than those in the correlated AFM-IR spectrum of NA erlotinib. Additionally, strengthening of the $1,570 \mathrm{~cm}^{-1}$ band is observed, as well as the appearance of a $1,488 \mathrm{~cm}^{-1}$ band that is not visible in the AFM-IR spectrum of erlotinib-AgNPs. Additionally, the observable band broadening $\left(\Delta_{\mathrm{FWHM}}=\sim 4 \mathrm{~cm}^{-1}\right)$ and position shift $\left(\Delta v=\sim 4 \mathrm{~cm}^{-1}\right)$ support the statement that the phenyl ring adsorbs on the AuNP mono-layer, and this interaction is even stronger than that on the AgNP mono-layer. This phenomenon is somewhat similar for the methoxy moiety. Here, the significantly pronounced bands at 1,515 and at $1,436,1,427,1,410 \mathrm{~cm}^{-1}$ due to the $\rho_{\mathrm{w}}\left(\mathrm{OCH}_{3}\right)$ and $\rho_{\mathrm{w}}\left(\mathrm{CH}_{2}\right)_{\mathrm{CH}_{3}}$ modes, respectively, together with the recorded changes in the band features $\left(\triangle_{\mathrm{FWHM}}=\sim 6 \mathrm{~cm}^{-1}\right.$ and $\left.\Delta v=\sim 6 \mathrm{~cm}^{-1}\right)$, suggest that in the erlotinib/AuNP mono-layer interaction, $-\mathrm{OCH}_{3}$ groups are strongly involved. There is some evidence indicating that the close proximity of the methoxy moiety to the AuNPs may result in charge transfer from the electropositive $-\mathrm{OCH}_{3}$ group to the metal [58]. It is known that molecules chemisorbed on metal surfaces exhibit large enhancements and changes in the band intensities [11]. This enhancement of the absorption coefficient of the adsorbed molecule may result in "intensity borrowing" from the charge oscillation between the metal and the molecule. However, this phenomenon is still not fully understood. The spectral features 
attributed to the amino and ethoxy groups may be interpreted in a same similar way. The bands appearing at $1,528 \mathrm{~cm}^{-1}$ $\left[\rho_{\mathrm{b}}(\mathrm{NH})\right]$ and $1,506 \mathrm{~cm}^{-1}\left[\rho_{\mathrm{s}}\left(\mathrm{CH}_{2}\right)_{\mathrm{OCH}_{2}}, \rho_{\mathrm{s}}\left(\mathrm{CH}_{2}\right)_{\mathrm{CH}_{2} \mathrm{O}}\right]$, show a significant enhancement and broadening (see Table 1) in comparison with those in the corresponding AFM-IR spectrum NA erlotinib. These functional groups are likely situated perpendicular to the AuNP mono-layer and participate directly in the adsorption process. Typically, for the interactions of the amino moiety with the negatively charged AuNP surface, electrostatic forces play the main role [59]. Figure 4 presents the suggested orientation of erlotinib on the AgNP and AuNP mono-layers.

As discussed in the Introduction, in conventional SEIRA spectroscopy, the enhancement is related to the increase in the local electromagnetic field generated by the localized surface plasmon resonance [7, 11-13]. For molecules located at "hot spots" (regions with strongly enhanced optical fields) [16], enormous enhancement of the signal thus occurs. Typically, single metal nanoparticles possess resonance bands in the visible spectral region [60]; however, they can be modified by tuning the appropriate size and morphology of the applied nanostructure [61], and for the metal islands and mono-layers, this range moves to the mid-IR region (end of the plasmon band) [13]. The localization of the electromagnetic field is strongly related to the shape of a nanostructure. It is commonly known that for isolated nanoparticles, the strongest field

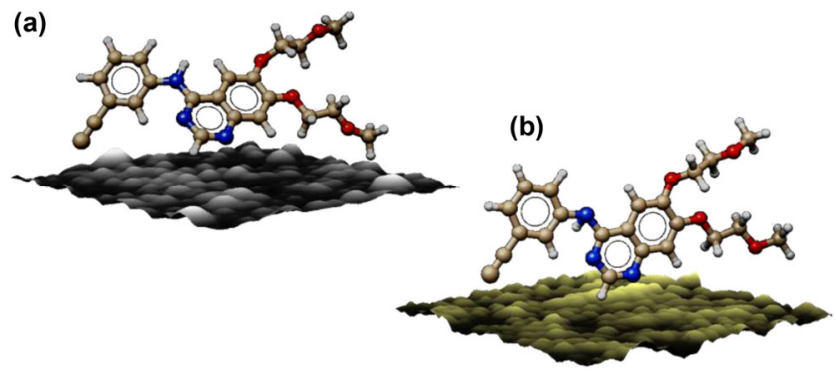

Figure 4 The suggested orientation of erlotinib adsorbed on the AgNPs (a) and AuNPs (b) mono-layers. amplification is distributed on their sharp edges [62]. Additionally, for anisotropic (non-spherical) nanoparticles, different modes of LSP can be excited due to the different polarization of incident light [63]. In the case of dimers or mono-layers of nanoparticles, the largest electromagnetic fields occur between them. The distance between nanoparticles determines the enhancement factor $[62,64]$. In SERS, the critical distance was indicated as equal to twice the nanoparticle diameter $[47,65]$. To obtain a sufficient enhancement visible in the SEIRA spectra, Ghosh and co-workers [47] indicate the limit of the gap size to be $5 \mathrm{~nm}$. A shorter distance ensures a higher enhancement [16]; however, according to the data published by Esteban and co-worker [66], a gap below $1 \mathrm{~nm}$ may suppress the near-field enhancement due to electron tunnelling. To better understand the surface enhancement effect with the AFM-IR technique, IR maps were acquired. Figure 5 illustrates the AFM topographies $(1 \mu \mathrm{m} \times 1 \mu \mathrm{m}(\mathrm{a})$ and $500 \mathrm{~nm} \times 500 \mathrm{~nm}(\mathrm{~b}))$ and the IR intensity map at $1,447 \mathrm{~cm}^{-1}$ (strongest absorption band attributed to $\left.v(\mathrm{CH})_{\text {Phe }}\right)$ of erlotinib-AgNPs. As discussed above, this absorption band was selected as a marker band for the presence of erlotinib (see Fig. 5(c)). Regions with a strong AFM-IR signal are visualized in red, while those with reduced intensity are coloured in blue. The area with the highest enhancement is localized between the nanoparticles, and the areas on the nanoparticles appear to manifest only negligible spectral signals. This phenomenon is even better observed on the $500 \mathrm{~nm} \times$ $500 \mathrm{~nm}$ 3D IR map at $1,447 \mathrm{~cm}^{-1}$ (see Fig. 5(d)) and suggests that the areas with a strong AFM-IR signal correspond to "hot spots" typically observed in the SEIRA effect.

For the AuNP mono-layer, the same experiments were performed. Like the Ag surface, the AFM-IR spectrum recorded on the Au surface exhibits strong IR absorption at $1,447 \mathrm{~cm}^{-1}$. Figure 6 shows the AFM topographies $(1 \mu \mathrm{m} \times 1 \mu \mathrm{m}$ (a) and $500 \mathrm{~nm} \times 500 \mathrm{~nm}(\mathrm{~b}))$ of the mono-layer and the 2D and 3D IR maps ((c) and (d), respectively) at $1,447 \mathrm{~cm}^{-1}$. For the AuNP mono-layer, the areas with strong enhancements appear to be located not only between the nanoparticles but also on top of some metal nanospheres. This phenomenon does not correspond

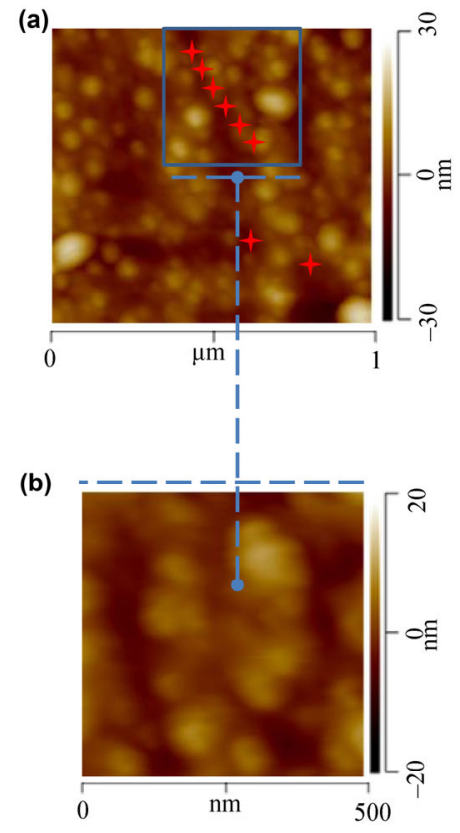

(c)
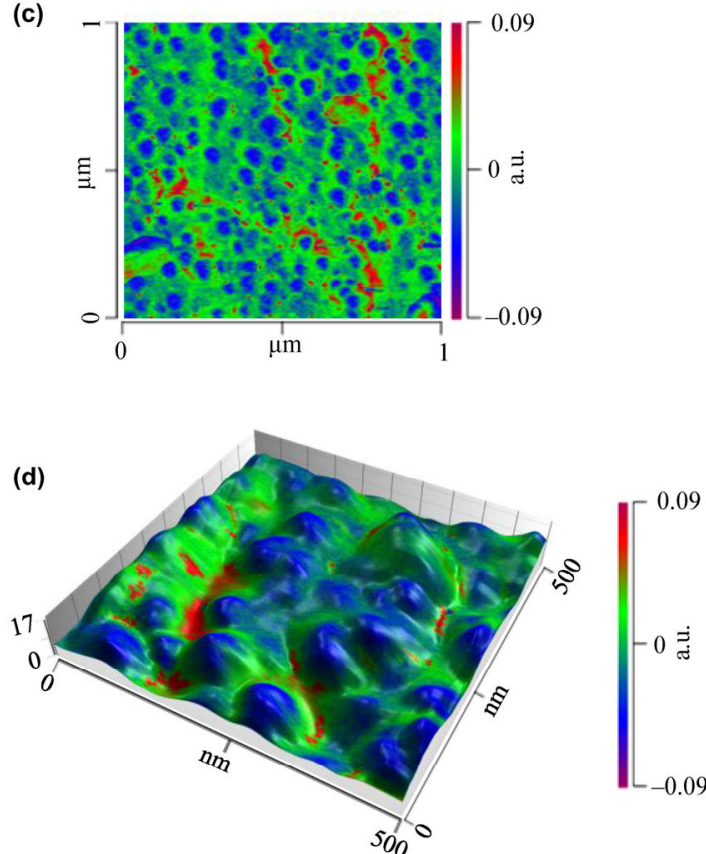

Figure 5 The AFM topographies $(1 \mu \mathrm{m} \times 1 \mu \mathrm{m}(\mathrm{a})$, and $500 \mathrm{~nm} \times 500 \mathrm{~nm}(\mathrm{~b}))$ of the AgNPs mono-layer with the adsorbed erlotinib together with the $2 \mathrm{D}$ and $3 \mathrm{D}$ AFM-IR intensity maps of the bands at $1,447 \mathrm{~cm}^{-1}((\mathrm{c})$ and $(\mathrm{d})$, respectively). The marked points show places from which the spectra were collected. 


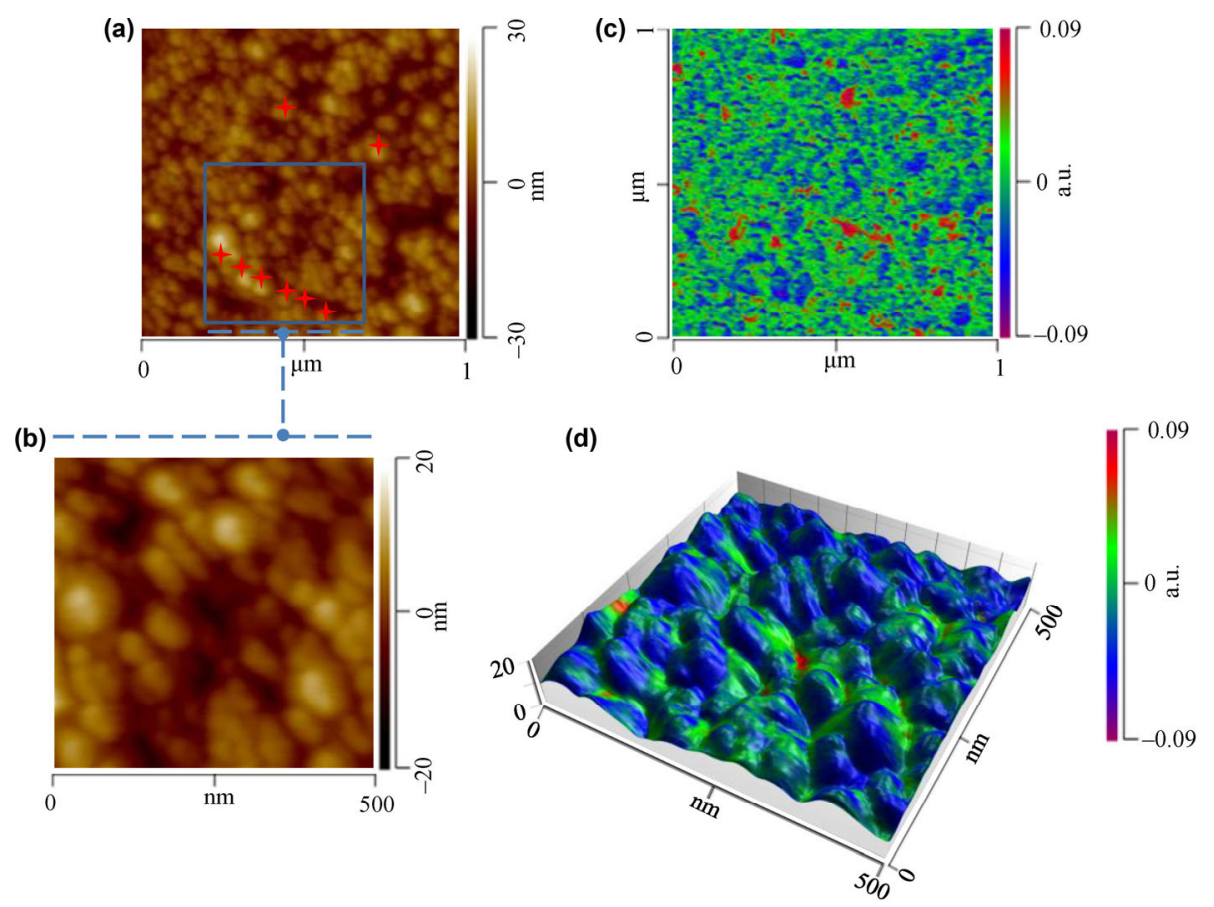

Figure 6 The AFM topographies $(1 \mu \mathrm{m} \times 1 \mu \mathrm{m}$ (a), and $500 \mathrm{~nm} \times 500 \mathrm{~nm}(\mathrm{~b}))$ of the AuNPs mono-layer with the adsorbed erlotinib together with the 2D and 3D AFM-IR intensity maps of the bands at $1,447 \mathrm{~cm}^{-1}((\mathrm{c})$ and $(\mathrm{d})$, respectively). The marked points show places from which the spectra were collected.

with the "hot spots" theory discussed above, which indicates that for spherical nanoparticles, the strongest electromagnetic field occurs between the particles. Thus, the regions with a very high intensity visible on the AFM-IR maps of the selected band may not be directly associated with the SEIRA "hot spots", but they may visualize the drug location. However, it seems that more evidence is needed to support this statement, and different drug/metal nanoparticle mono-layer systems should be tested for further verification.

Another important issue should also be considered. The gold-coated tip together with the gold-coated surface may promote induction of an optical field appearing in the nanogap between them [67]. At the moment, it is difficult to determine the role of the AFM tip in the SEIRA effect discussed within these studies. An experimental approach combining complementary measurements using two different AFM-IR systems-one with illumination from the bottom, where a silicon tip (uncoated) is employed (NanoIR1), and the other with illumination from the top, with a gold-coated tip (NanoIR2) - on the same molecule-metal nanoparticle system should be able to answer the question regarding the hypothetical tip effect.

\section{Conclusions}

In this study, the first tapping AFM-IR investigations were performed to understand erlotinib adsorption on AgNP and AuNP mono-layers. The AFM-IR spectra collected for the drug alone and after its immobilization on a metal mono-layer exhibit crucial spectral differences, namely, changes in the relative intensities, bandwidths and shifts in their positions. Such phenomena prove that this nanospectroscopy technique in connection with techniques such as SERS can be successfully applied for in-depth molecular adsorption characterization. Additionally, the obtained results match very well with previously published data for this drug adsorbed on AgNPs dispersed in suspensions [44]. This fact is also important because the metal surface selection rules used for adsorption geometry interpretation of typical SEIRA spectra, which are commonly known and well characterized $[8,9]$, provided reliable conclusions for the AFM-IR technique. These results prove the statement that the AFM-IR technique used to investigate molecules adsorbed on the roughened metal nanostructure could be considered a nanospectroscopy technique sensitive to the SEIRA effect. Based on the obtained data, we indicate that erlotinib interacts with the AgNP mono-layer via the phenyl ring and methoxy moiety. However, the quinazoline, amino, and ethoxy groups are situated farther from the mono-layer and do not interact directly with the NPs. For the drug immobilized on the AuNP mono-layer, another slightly different spectral pattern was observed. Here, erlotinib molecules adsorb through the phenyl ring and the quinazoline moiety. The amino, methoxy, and ethoxy groups exhibit less of an interaction with this metal mono-layer.

Additionally, the corresponding AFM-IR maps (for erlotinibAgNPs and erlotinib-AuNPs) show areas with very strong signals. Do these places correspond either to the typical "hot spots" observed for the SERS and SEIRA techniques or to drug distribution? The obtained data may suggest that the strong enhancement is associated with the localization of the drug-preferentially between the nanoparticles for the AgNP mono-layer, but more homogenous for the AuNP mono-layer. However, more AFM-IR investigations of different drug/metal nanoparticle mono-layer systems have to be performed in order to support this statement. Simultaneously, the question regarding the role of the gold-coated tip applied in the considered measurements is still open, and as discussed above, a more comprehensive experimental approach to explain the hypothetical tip effect is needed.

\section{Acknowledgements}

This work was supported by the National Science Centre Poland (No. 2016/21/D/ST4/02178 to N. P.). N. P. gratefully acknowledges the financial support of the French Government and the French Embassy in Poland. These researches were also supported by the Paris Ile-de-France Region-DIM Materiaux anciens et patrimoniaux. The measurements were partly 
performed using the equipment purchased in the frame of the project co-funded by the MałopolskaRegional Operational Program Measure 5.1 Krakow Metropolitan Areaas an important hub of the European Research Area for 2007-2013, project no. MRPO.05.01.00-12-013/15e.

Open Access This article is licensed under a Creative Commons Attribution 4.0 International License, which permits use, sharing, adaptation, distribution and reproduction in any medium or format, as long as you give appropriate credit to the original author(s) and the source, provide a link to the Creative Commons licence, and indicate if changes were made.

The images or other third party material in this article are included in the article's Creative Commons licence, unless indicated otherwise in a credit line to the material. If material is not included in the article's Creative Commons licence and your intended use is not permitted by statutory regulation or exceeds the permitted use, you will need to obtain permission directly from the copyright holder.

To view a copy of this licence, visit http://creativecommons.org/ licenses/by/4.0/.

\section{References}

[1] Chen, S. Z.; Hao, X. H.; Liang, X. J.; Zhang, Q.; Zhang, C. M.; Zhou, G. Q.; Shen, S. G.; Jia, G.; Zhang, J. C. Inorganic nanomaterials as carriers for drug delivery. J. Biomed. Nanotechnol. 2016, $12,1-27$.

[2] Cho, H. Y.; Lee, Y. B. Nano-sized drug delivery systems for lymphatic delivery. J. Nanosci. Nanotechnol. 2014, 14, 868-880.

[3] Zhang, J.; Yuan, Z. F.; Wang, Y.; Chen, W. H.; Luo, G. F.; Cheng, S. X.; Zhuo, R. X.; Zhang, X. Z. Multifunctional envelope-type mesoporous silica nanoparticles for tumor-triggered targeting drug delivery. J. Am. Chem. Soc. 2013, 135, 5068-5073.

[4] Cross, M. J.; Berridge, B. R.; Clements, P. J. M.; Cove-Smith, L.; Force, T. L.; Hoffmann, P.; Holbrook, M.; Lyon, A. R.; Mellor, H. R.; Norris, A. A. et al. Physiological, pharmacological and toxicological considerations of drug-induced structural cardiac injury. $\mathrm{Br} . \mathrm{J}$. Pharmacol. 2015, 172, 957-974.

[5] Da Silva, C. G.; Peters, G. J.; Ossendorp, F.; Cruz, L. J. The potential of multi-compound nanoparticles to bypass drug resistance in cancer. Cancer Chemother. Pharmacol. 2017, 80, 881-894.

[6] Fleischmann, M.; Hendra, P. J; McQuillan, A. J. Raman spectra of pyridine adsorbed at a silver electrode. Chem. Phys. Lett. 1974, 26, 163-166.

[7] Masatoshi, O. Dynamic processes in electrochemical reactions studied by surface-enhanced infrared absorption spectroscopy (SEIRAS). Bull. Chem. Soc. Jpn. 1997, 70, 2861-2880.

[8] Brundle, C. R.; Morawitz, H. Vibrations at Surfaces; Elsevier: Amsterdam, 1983.

[9] Pearce, H. A.; Sheppard, N. Possible importance of a "metal-surface selection rule" in the interpretation of the infrared spectra of molecules adsorbed on particulate metals; infrared spectra from ethylene chemisorbed on silica-supported metal catalysts. Surf. Sci. 1976, 59, 205-217.

[10] Greenler, R. G.; Snider, D. R.; Witt, D.; Sorbello, R. S. The metalsurface selection rule for infrared spectra of molecules adsorbed on small metal particles. Surf. Sci. 1982, 118, 415-428.

[11] Osawa, M. Surface-enhanced infrared absorption. In Near-Field Optics and Surface Plasmon Polaritons. Kawata, S., Ed.; Springer: Berlin, Heidelberg, 2001; pp 163-187.

[12] Huck, C.; Neubrech, F.; Vogt, J.; Toma, A.; Gerbert, D.; Katzmann, J.; Härtling, T.; Pucci, A. Surface-enhanced infrared spectroscopy using nanometer-sized gaps. ACS Nano 2014, 8, 4908-4914.

[13] Kundu, J.; Le, F.; Nordlander, P.; Halas, N. J. Surface enhanced infrared absorption (SEIRA) spectroscopy on nanoshell aggregate substrates. Chem. Phys. Lett. 2008, 452, 115-119.

[14] Gersten, J. I.; Nitzan, A. Photophysics and photochemistry near surfaces and small particles. Surf. Sci. 1985, 158, 165-189.
[15] Otto, A.; Mrozek, I.; Grabhorn, H.; Akemann, W. Surface-enhanced Raman scattering. J. Phys. Condens. Matter 1992, 4, 1143-1212.

[16] Alonso-González, P.; Albella, P.; Schnell, M.; Chen, J.; Huth, F.; García-Etxarri, A.; Casanova, F.; Golmar, F.; Arzubiaga, L.; Hueso, L. E. et al. Resolving the electromagnetic mechanism of surfaceenhanced light scattering at single hot spots. Nat. Commun. 2012, 3,684 .

[17] Ueno, K.; Sun, Q.; Mino, M.; Itoh, T.; Oshikiri, T.; Misawa, H. Surface plasmon optical antennae in the infrared region with high resonant efficiency and frequency selectivity. Opt. Express 2016, 24, $17728-17737$.

[18] Haynes, C. L.; McFarland, A. D.; Zhao, L. L.; van Duyne, R. P.; Schatz, G. C.; Gunnarsson, L.; Prikulis, J.; Kasemo, B.; Käll, M. Nanoparticle optics: The importance of radiative dipole coupling in two-dimensional nanoparticle arrays. J. Phys. Chem. B 2003, 107, 7337-7342.

[19] Pucci, A.; Neubrech, F.; Weber, D.; Hong, S.; Toury, T.; Lamy de la Chapelle, M. Surface enhanced infrared spectroscopy using gold nanoantennas. Phys. Status Solid B 2010, 247, 2071-2074.

[20] Lasch, P.; Naumann, D. Spatial resolution in infrared microspectroscopic imaging of tissues. Biochim. Biophys. Acta 2006, 1758, 814-829.

[21] Reddy, R. K.; Walsh, M. J.; Schulmerich, M. V.; Carney, P. S.; Bhargava, R. High-definition infrared spectroscopic imaging. Appl. Spectrosc. 2013, 67, 93-105.

[22] Dazzi, A.; Prater, C. B. AFM-IR: Technology and applications in nanoscale infrared spectroscopy and chemical imaging. Chem. Rev. 2017, 117, 5146-5173.

[23] Dazzi, A.; Prater, C. B.; Hu, Q. C.; Chase, D. B.; Rabolt, J. F.; Marcott, C. AFM-IR: Combining atomic force microscopy and infrared spectroscopy for nanoscale chemical characterization. Appl. Spectrosc. 2012, 66, 1365-1384.

[24] Khanal, D.; Kondyurin, A.; Hau, H.; Knowles, J. C.; Levinson, O.; Ramzan, I.; Fu, D.; Marcott, C.; Chrzanowski, W. Biospectroscopy of nanodiamond-induced alterations in conformation of intra- and extracellular proteins: A nanoscale IR study. Anal. Chem. 2016, 88 , 7530-7538.

[25] Dazzi, A.; Glotin, F.; Carminati, R. Theory of infrared nanospectroscopy by photothermal induced resonance. J. Appl. Phys. 2010, 107, 124519.

[26] Dazzi, A.; Prazeres, R.; Glotin, F.; Ortega, J. M. Local infrared microspectroscopy with subwavelength spatial resolution with an atomic force microscope tip used as a photothermal sensor. Opt. Lett. 2005, 30, 2388-2390.

[27] Kennedy, E.; Al-Majmaie, R.; Al-Rubeai, M. Quantifying nanoscale biochemical heterogeneity in human epithelial cancer cells using combined AFM and PTIR absorption nanoimaging. J. Biophotonics 2015, 8, 133-141.

[28] Policar, C.; Waern, J. B.; Plamont, M. A.; Clède, S.; Mayet, C.; Prazeres, R.; Ortega, J. M.; Vessières, A.; Dazzi, A. Subcellular IR imaging of a metal-carbonyl moiety using photothermally induced resonance. Angew. Chem. 2011, 123, 890-894.

[29] Deniset-Besseau, A.; Prater, C. B.; Virolle, M. J.; Dazzi, A. Monitoring triacylglycerols accumulation by atomic force microscopy based infrared spectroscopy in streptomyces species for biodiesel applications. J. Phys. Chem. Lett. 2014, 5, 654-658.

[30] Mayet, C.; Dazzi, A.; Prazeres, R.; Ortega, J. M.; Jaillard, D. In situ identification and imaging of bacterial polymer nanogranules by infrared nanospectroscopy. Analyst 2010, 135, 2540-2545.

[31] Marcott, C.; Lo, M.; Kjoller, K.; Domanov, Y.; Balooch, G.; Luengo, G. S. Nanoscale infrared (IR) spectroscopy and imaging of structural lipids in human stratum corneum using an atomic force microscope to directly detect absorbed light from a tunable IR laser source. Exp. Dermatol. 2013, 22, 419-421.

[32] Paluszkiewicz, C. Piergies, N.; Chaniecki, P.; Rękas, M.; Miszczyk, J.; Kwiatek, W. M. Differentiation of protein secondary structure in clear and opaque human lenses: AFM-IR studies. J. Pharm. Biomed. Anal. 2017, 139, 125-132.

[33] Mikhalchan, A.; Banas, A. M.; Banas, K.; Borkowska, A. M.; Nowakowski, M.; Breese, M. B. H.; Kwiatek, W. M.; Paluszkiewicz, C.; Tay, T. E. Revealing chemical heterogeneity of CNT fiber nanocomposites via nanoscale chemical imaging. Chem. Mater. 2018, 30, 1856-1864. 
[34] Latour, G.; Robinet, L.; Dazzi, A.; Portier, F.; Deniset-Besseau, A.; Schanne-Klein, M. C. Correlative nonlinear optical microscopy and infrared nanoscopy reveals collagen degradation in altered parchments. Sci. Rep. 2016, 6, 26344.

[35] Mathurin, J; Pancani, E; Deniset-Besseau, A; Kjoller, K; Prater, C. B; Gref, R; Dazzi, A. How to unravel the chemical structure and component localization of individual drug-loaded polymeric nanoparticles by using tapping AFM-IR. Analyst 2018, 143, 5940-5949.

[36] Tuteja, M; Kang, M; Leal, C; Centrone, A. Nanoscale partitioning of paclitaxel in hybrid lipid-polymer membranes. Analyst 2018, 143, 3808-3813.

[37] Piergies, N.; Pięta, E.; Paluszkiewicz, C.; Domin, H.; Kwiatek, W. M. Polarization effect in tip-enhanced infrared nanospectroscopy studies of the selective Y5 receptor antagonist Lu AA33810. Nano Res. 2018, 11, 4401-4411.

[38] Pięta, E.; Paluszkiewicz, C.; Kwiatek, W. M. Multianalytical approach for surface- and tip-enhanced infrared spectroscopy study of a molecule--metal conjugate: Deducing its adsorption geometry. Phys. Chem. Chem. Phys. 2018, 20, 27992-28000.

[39] Arora, A.; Scholar, E. M. Role of tyrosine kinase inhibitors in cancer therapy. J. Pharmacol. Exp. Ther. 2005, 315, 971-979.

[40] Pearson, M. A.; Fabbro, D. Targeting protein kinases in cancer therapy: A success? Expert Rev. Anticancer Ther. 2004, 4, 1113-1124.

[41] Gorzalczany, Y.; Gilad, Y.; Amihai, D.; Hammel, I.; Sagi-Eisenberg, R.; Merimsky, O. Combining an EGFR directed tyrosine kinase inhibitor with autophagy-inducing drugs: A beneficial strategy to combat non-small cell lung cancer. Cancer Lett. 2011, 310, 207-215.

[42] Lacouture, M. E. Mechanisms of cutaneous toxicities to EGFR inhibitors. Nat. Rev. Cancer 2006, 6, 803-812.

[43] Bianchini, D.; Jayanth, A.; Chua, Y. J.; Cunningham, D. Epidermal growth factor receptor inhibitor-related skin toxicity: Mechanisms, treatment, and its potential role as a predictive marker. Clin. Colorectal Cancer 2008, 7, 33-43.

[44] Piergies, N.; Oćwieja, M.; Paluszkiewicz, C.; Kwiatek, W. M. Identification of erlotinib adsorption pattern onto silver nanoparticles: SERS studies. J. Raman Spectrosc. 2018, 49, 1265-1273.

[45] Oćwieja, M.; Adamczyk, Z. Controlled release of silver nanoparticles from monolayers deposited on PAH covered mica. Langmuir 2013, 29, 3546-3555.

[46] Maciejewska-Prończuk, J.; Morga, M.; Adamczyk, Z.; Oćwieja, M.; Zimowska, M. Homogeneous gold nanoparticle monolayers-QCM and electrokinetic characteristics. Colloids Surf. A 2017, 514, 226-235.

[47] Ghosh, H.; Bürgi, T. Mapping infrared enhancement around gold nanoparticles using polyelectrolytes. J. Phys. Chem. C 2017, 121, 2355-2363.

[48] Piergies, N.; Paluszkiewicz, C.; Kwiatek, W. M. Vibrational fingerprint of erlotinib: FTIR, RS, and DFT studies. J. Spectrosc. 2019, 2019, 9191328.

[49] Qi, Y. J.; Hu, Y. J.; Xie, M.; Xing, D.; Gu, H. M. Adsorption of aniline on silver mirror studied by surface-enhanced Raman scattering spectroscopy and density functional theory calculations. J. Raman Spectrosc. 2011, 42, 1287-1293.

[50] Dornhaus, R.; Long, M. B.; Benner, R. E.; Chang, R. K. Time development of SERS from pyridine, pyrimidine, pyrazine, and cyanide adsorbed on Ag electrodes during an oxidation-reduction cycle. Surf. Sci. 1980, 93, 240-262.

[51] Muniz-Miranda, M.; Neto, N.; Sbrana, G. Surface-enhanced Raman spectra of pyrazine, pyrimidine, and pyridazine adsorbed on silver sols. J. Phys. Chem. 1988, 92, 954-959.

[52] Lee, T. W.; Kim, K.; Kim, M. S. Raman spectroscopy of phenylacetylene adsorbed on silver surfaces. J. Mol. Struct. 1992, 274, 59-73.

[53] Coates, J. Interpretation of infrared spectra, a practical approach. In Encyclopedia of Analytical Chemistry. Meyer, R. A., Ed.; John Wiley \& Sons Ltd: Chichester, 2000; pp 1-23.

[54] Varfolomeev, M. A.; Abaidullina, D. I.; Klimovitskii, A. E.; Solomonov, B. N. Solvent effect on stretching vibration frequencies of the N-H and $\mathrm{O}-\mathrm{H}$ groups of diphenylamine and phenol in complexes with various proton acceptors: Cooperative effect. Russ. J. Gen. Chem. 2007, 77, 1742-1748.

[55] King, P. L.; Ramsey, M. S.; McMillan, P. F.; Swayze, G. A. Laboratory Fourier transform infrared spectroscopy methods for geologic samples. In Infrared Spectroscopy in Geochemistry, Exploration Geochemistry, and Remote Sensing. King, P. L.; Ramsey, M. S.; Swayze, G. A., Eds.; Mineralogical Association of Canada: London, 2004; pp 57-92.

[56] Xiong, M.; Ye, J. Reproducibility in surface-enhanced Raman spectroscopy. J. Shanghai Jiaotong Univ. (Sci.) 2014, 19, 681-690

[57] Dovbeshko, G.; Fesenko, O.; Chegel, V.; Shirshov, Y.; Kosenkov, D.; Nazarova, A. Effect of nanostructured gold surface on the SEIRA spectra of nucleic acid, albumin, $\alpha$-glycine and guanine. Asian Chem. Lett. 2006, 10, 33-44.

[58] Fudickar, W.; Pavashe, P.; Linker, T. Thiocarbohydrates on gold nanoparticles: Strong influence of stereocenters on binding affinity and interparticle forces. Chem. -Eur. J. 2017, 23, 8685-8693.

[59] Guerrini, L.; Jurasekova, Z.; Domingo, C.; Pérez-Méndez, M.; Leyton, P.; Campos-Vallette, M.; Garcia-Ramos, J. V.; Sanchez-Cortes, $\mathrm{S}$. Importance of metal-adsorbate interactions for the surface-enhanced Raman scattering of molecules adsorbed on plasmonic nanoparticles. Plasmonics 2007, 2, 147-156.

[60] Garcia, M. A. Surface plasmons in metallic nanoparticles: Fundamentals and applications. J. Phys. D Appl. Phys. 2011, 44, 283001.

[61] Castro, L.; Blázquez, M. L.; Muñoz, J. Á.; González, F. G.; Ballester, A. Mechanism and applications of metal nanoparticles prepared by bio-mediated process. Rev. Adv. Sci. Eng. 2014, 3, 199-216.

[62] Krajczewski, J.; Kołątaj, K.; Kudelski, A. Plasmonic nanoparticles in chemical analysis. RSC Adv. 2017, 7, 17559-17576.

[63] Abdulhalim, I. Coupling configurations between extended surface electromagnetic waves and localized surface plasmons for ultrahigh field enhancement. Nanophotonics 2018, 7, 1891-1916.

[64] Ghosh, S. K.; Pal, T. Interparticle coupling effect on the surface plasmon resonance of gold nanoparticles: From theory to applications. Chem. Rev. 2007, 107, 4797-4862.

[65] Zhu, Z. H.; Zhu, T.; Liu, Z. F. Raman scattering enhancement contributed from individual gold nanoparticles and interparticle coupling. Nanotechnology 2004, 15, 357-364.

[66] Esteban, R.; Borisov, A. G.; Nordlander, P.; Aizpurua, J. Bridging quantum and classical plasmonics with a quantum-corrected model. Nat. Commun. 2012, 3, 825.

[67] Lu, F.; Jin, M. Z.; Belkin, M. A. Tip-enhanced infrared nanospectroscopy via molecular expansion force detection. Nat. Photonics 2014, 8, 307-312. 